\title{
Characterization of NrnA homologs from Mycobacterium tuberculosis and Mycoplasma pneumoniae
}

\author{
GUILLAUME POSTIC, ${ }^{1,4}$ ANTOINE DANCHIN, ${ }^{1,2}$ and UNDINE MECHOLD ${ }^{1,3,5}$ \\ ${ }^{1}$ Unité de Génétique des Génomes Bactériens, Institut Pasteur, CNRS URA 2171, 75724 Paris Cedex 15, France \\ ${ }^{2}$ AMAbiotics, 91030 Evry Cedex, France \\ ${ }^{3}$ Unité de Biochimie des Interactions macromoléculaires CNRS URA 2185, 75724 Paris Cedex 15, France
}

\begin{abstract}
Processive RNases are unable to degrade efficiently very short oligonucleotides, and they are complemented by specific enzymes, nanoRNases, that assist in this process. We previously identified NrnA (Ytql) from Bacillus subtilis as a bifunctional protein with the ability to degrade nanoRNA (RNA oligos $\leq 5$ nucleotides) and to dephosphorylate 3 '-phosphoadenosine $5^{\prime}$-phosphate (pAp) to AMP. While the former activity is analogous to that of oligoribonuclease (Orn) from Escherichia coli, the latter corresponds to CysQ. NrnA homologs are widely present in bacterial and archaeal genomes. They are found preferably in genomes that lack Orn or CysQ homologs. Here, we characterize NrnA homologs from important human pathogens, Mpn140 from Mycoplasma pneumoniae, and Rv2837c from Mycobacterium tuberculosis. Like NrnA, these enzymes degrade nanoRNA and dephosphorylate pAp in vitro. However, they show dissimilar preferences for specific nanoRNA substrate lengths. Whereas NrnA prefers RNA 3-mers with a 10-fold higher specific activity compared to 5-mers, Rv2837c shows a preference for nanoRNA of a different length, namely, 2-mers. Mpn140 degrades Cy5labeled nanoRNA substrates in vitro with activities varying within one order of magnitude as follows: 5-mer>4-mer>3mer>2-mer. In agreement with these in vitro activities, both Rv2837c and Mpn140 can complement the lack of their functional counterparts in E. coli: CysQ and Orn. The NrnA homolog from Streptococcus mutans, SMU.1297, was previously shown to hydrolyze pAp and to complement an $E$. coli cys $Q$ mutant. Here, we show that SMU.1297 can complement an $E$. coli orn ${ }^{-}$mutant, suggesting that having both pAp-phosphatase and nanoRNase activity is a common feature of NrnA homologs.
\end{abstract}

Keywords: nanoRNA; NrnA; pAp; CysQ; bifunctionality

\section{INTRODUCTION}

Analysis of RNA degradation demonstrated that most RNases are incapable of completing the degradation of RNA to the point where only nucleotide monomers remain. Instead, these enzymes have a specific RNA chain size limit that, once approached, causes the release of the remaining RNA chain. As an example, the released chain lengths produced by RNase II and RNase R were found to be 3-5-mers (Cheng and Deutscher 2002) or 4-6-mers (Amblar et al. 2006, 2007), and 2-3-mers (Cheng and Deutscher 2002; Vincent and Deutscher 2006) or 1-2-mers (Amblar et al. 2007), respectively. The

\footnotetext{
${ }^{4}$ Present address: Unité de Pathogénie des Infections Systémiques, Inserm 1002, Université Paris Descartes, Sorbonne Paris Cité, Faculté de Médecine, 75730 Paris Cedex 15, France.

${ }^{5}$ Corresponding author.

E-mail undine.mechold@pasteur.fr.

Article published online ahead of print. Article and publication date are at http://www.rnajournal.org/cgi/doi/10.1261/rna.029132.111.
}

mechanistic basis for this size limit was explained nicely by structural insights provided by the example of RNase II, where binding of a relatively long RNA molecule is important for stabilizing the catalytic complex (Cheng and Deutscher 2002; Frazao et al. 2006; Vincent and Deutscher 2006; Amblar et al. 2007). This constraint has therefore to be considered in the design of synthetic cells. We previously introduced the term "nanoRNA" in order to distinguish these extremely short oligonucleotides of five residues and shorter in length from the longer microRNAs with known explicit functions in the cell (Mechold et al. 2007; Fang et al. 2009).

In line with the importance of their action, the function of nanoRNases is ubiquitously present. However, their phylogenetic origin is multiple. In Escherichia coli, a single exoribonuclease is capable of degrading nanoRNA: This is oligoribonuclease (Orn) (Yu and Deutscher 1995; Zhang et al. 1998; Ghosh and Deutscher 1999). In the absence of Orn activity, nanoRNA was shown to accumulate (Ghosh and Deutscher 1999). Orn is essential in E. coli, suggesting 
that accumulation of nanoRNA is detrimental for the cells. Recent data show that nanoRNA can serve as primers for transcription and that this leads to changes in global gene expression under conditions of artificially elevated nanoRNA concentrations (Goldman et al. 2011; Nickels and Dove 2011).

Orn orthologs are present in $\beta$ - and $\gamma$-proteobacteria, in actinobacteria, and in many eukaryotic genomes. However, there are a substantial number of bacterial species that do not have Orn orthologs, among them the large group of Firmicutes, which includes the model bacterium Bacillus subtilis. We demonstrated in a previous work that in $B$. subtilis, the situation is quite different from that in E. coli; here, the degradation of nanoRNA is catalyzed by multiple redundant RNases (Fang et al. 2009). We have identified two enzymes with nanoRNase activity in B. subtilis: YtqI (now renamed NrnA for nanoRNase $\underline{A}$ ) (Mechold et al. 2007) and YngD (now NrnB) (Fang et al. 2009). Remarkably, NrnA was shown not only to be required for scavenging nanoRNAs but also to be necessary for the dephosphorylation of $3^{\prime}$ phosphoadenosine $5^{\prime}$-phosphate (pAp), a side-product of sulfur assimilation and acyl carrier proteins (ACPs) synthesis.

NrnA was first shown to bind to pAp and tested as a putative nanoRNase by analogy with the conserved strong interaction between pAp and some nanoRNases, previously demonstrated for Orn (E. coli) and its human homolog Sfn (Mechold et al. 2006). We showed that NrnA degrades nanoRNA in vitro and can complement the lack of nanoRNase activity in an E. coli orn $^{-}$mutant. In addition to its nanoRNase activity, NrnA is also able to convert pAp to AMP in vitro and to complement a mutant in the E. coli gene $c y s Q$, which codes for $\mathrm{pAp}$ phosphatase. Consistent with this second activity of NrnA, the phenotype of an $n r n A$ mutant in B. subtilis is similar to that of an E. coli cys $Q$ mutant, namely, a growth defect in the absence of cysteine, thus pointing to the coupling of RNA turnover and sulfur metabolism.

$\mathrm{NrnB}$, a second nanoRNase in B. subtilis, was identified by screening a genomic library for genes that can complement a conditional orn mutant in E. coli (Fang et al. 2009). NrnB is present in a small number of genomes. Many of the species that have NrnB are closely related to B. subtilis; however, it can be also found in $\varepsilon$-proteobacteria such as Helicobacter spp. and Campylobacter spp. that have neither Orn nor NrnA.

$\mathrm{NrnA}$, on the other hand, is widely present in bacterial genomes, where it can be found mainly in genomes that do not harbor orn homologs, among them Firmicutes, as already mentioned, but also Bacteroidetes, Chlorobi, and species of the $\delta$ subdivision of Proteobacteria. Many of these species also lack CysQ, adding additional support for the bifunctional nature of NrnA.

To test whether this unexpected bifunctionality is a common feature of NrnA homologs, we here characterized two NrnA homologs from important human pathogens: Mpn140 from Mycoplasma pneumoniae and Rv2837c from Mycobacterium tuberculosis, the causative agent of Tuberculosis, an organism in which one finds counterparts of both Orn and NrnA.
The former causes atypical pneumonia that can manifest itself at extrapulmonary sites and lead to serious complications (Waites and Talkington 2004). With only 689 protein-coding genes (Himmelreich et al. 1996; Dandekar et al. 2000; Yus et al. 2009), M. pneumoniae has one of the smallest genomes of autonomously replicating cells. Despite the small genome, 231 of the encoded proteins, including Mpn140, are of unknown function. We show here that the NrnA homologs from both M. tuberculosis (Rv2837c) and M. pneumoniae (Mpn140) are bifunctional, whereas their preferences for specific nanoRNA substrate lengths, however, differ.

In addition, we demonstrate that SMU.1297 from Streptococcus mutans, which was previously shown to dephosphorylate pAp in vitro and to complement an E. coli cysQ mutant (Zhang and Biswas 2009), can also complement a conditional E. coli orn mutant. Our results suggest that the ability to hydrolyze both pAp and nanoRNA is a common feature of NrnA homologs.

\section{RESULTS}

To determine whether bifunctionality is a common trait of NrnA homologs, we identified orthologs of NrnA in $M$. tuberculosis and M. pneumoniae. Rv2837C and Mpn140 are bidirectional best hits of NrnA in M. tuberculosis and M. pneumoniae, respectively: BLAST searches using NrnA as input retrieved these proteins as best hits in the indicated genome, and BLAST searches for orthologs of Rv2837c and Mpn140 in B. subtilis retrieved NrnA as a best hit. Identity and similarity between $\mathrm{NrnA}$ and Rv2837c are 25\% and $41 \%$, respectively. Identity and similarity between NrnA and Mpn 140 are $32 \%$ and 52\%, respectively. The similarity in length between NrnA and the two identified orthologs (Rv2837c and Mpn140 are 107\% and 103.5\%, respectively, the length of NrnA) were additional criteria that served to define them as orthologs.

The amino acid sequences of Rv2837C and Mpn140 show $23 \%$ identity and $43 \%$ similarity.

\section{Rv2837c and Mpn140 complement an E. coli orn $^{-}$mutant}

As a first step of testing Rv2837c and Mpn140 for nanoRNase activity, we determined whether their expression can rescue the growth defect of our conditional promoter mutant of the essential E. coli orn. This mutant (strain UM341, see Table 1) (Mechold et al. 2007) uses the anhydrotetracycline (Atc)inducible promoter $\mathrm{P}_{\mathrm{LtetO}-1}$ (Lutz and Bujard 1997) together with a Tet-repressor (TetR) to ensure tight control in the absence of Atc. A growth defect of UM341 could easily be observed in the absence of Atc; transformants of this strain with pBAD18 produced pinpoint-sized colonies that stopped growing, whereas transformants with the orncarrying plasmid (pUM408) were significantly larger after overnight growth and continued to grow (Fig. 1). 
TABLE 1. Bacterial strains, plasmids, and primers

\begin{tabular}{|c|c|c|}
\hline & Description & Reference \\
\hline \multicolumn{3}{|l|}{ Strains } \\
\hline MG1655 & E. coli $K 12$ wild type & \\
\hline CF10230 & nic+ derivative of DY329 & M Cashel, unpubl. \\
\hline UM285 & As CF10230 but $\Delta c y s Q, \mathrm{Km}^{\mathrm{R}}$ & Mechold et al. (2006) \\
\hline UM341 & As CF10230 but orn under control of $\mathrm{P}_{\text {LtetO-1 }}$, TetR, $\mathrm{Km}^{\mathrm{R}}$ & Mechold et al. (2007) \\
\hline \multicolumn{3}{|c|}{ 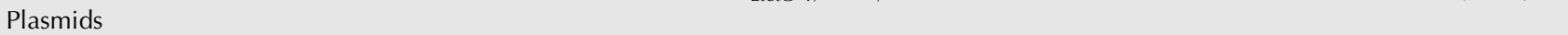 } \\
\hline pBAD18 & Vector, $\mathrm{P}_{\text {ara }} \mathrm{pBR}$ replicon, $A \mathrm{p}^{\mathrm{R}}$ & Guzman et al. (1995) \\
\hline pGEM-T Easy & Vector for TA cloning & Promega \\
\hline pUM404 & As pBAD18, CysQ with C-terminal his-tag & Mechold et al. (2006) \\
\hline pUM408 & As pBAD18, Orn with C-terminal his-tag & Mechold et al. (2006) \\
\hline pUM415 & As pBAD18, Rv2837c with C-terminal his-tag & This study \\
\hline pUM417 & As pUC18, Rv2837c with C-terminal his-tag in orientation of $\mathrm{P}_{l a c}$ & This study \\
\hline pUM428 & As pUC18, Rv2837c under control of its native promoter, in orientation of $\mathrm{P}_{\text {lac }}$ & This study \\
\hline pUM441 & As pBAD18, Mpn140 with C-terminal his-tag & This study \\
\hline pGP1 & As pUM441, but Mpn140 (D118A, H119A, H120A) with C-terminal his-tag & This study \\
\hline pOri23 & E. coli/Lactococcus lactis shuttle vector, $\mathrm{Em}^{\mathrm{R}}$ & Que et al. (2000) \\
\hline plB1297 & As pOri23, SMU.1297 & Zhang and Biswas (2009) \\
\hline pASK-IBA43plus & Commercial vector, $P_{\text {tet, }} A p^{R}$ & IBA-Biotechnology \\
\hline plB900 & As pASK-IBA43plus, SMU.1297 with N-terminal his-tag & Zhang and Biswas (2009) \\
\hline \multicolumn{3}{|l|}{ Primers } \\
\hline UM181 & 5'-GGGGAATTCACCatgacgacgatcgacccaag-3' & \\
\hline UM182 & 5'-GAAACTCGAGaccaagcgccgcgcgcaac-3' & \\
\hline UM192 & 5'-GGGGAATTCAAGAAGGAGATATACCATGACGACGATCGACCCAA-3' & \\
\hline UM193 & 5'-ATATCTAGAGGATCCCCTCAGCGGT-3' & \\
\hline UM199 & 5'-TTTGCATGCCTAACCAAGCGCCGCGCGCAA-3' & \\
\hline UM212 & 5'-CCGGCTAGCAGGAGGAATTCACCATGAATAGCCAAGTACACCGC-3' & \\
\hline UM213 & 5'-GGGCTCGAGTACAGCAATTTGCTTTTGGC-3' & \\
\hline UM229 & $5^{\prime}$-cacaactttccctggttggagatggttttc- $3^{\prime}$ & \\
\hline UM231 & $5^{\prime}$-gaaaaccatctccaaccagggaaagttgtg-3' & \\
\hline UM234 & 5'-GGGgagctctatatagcatagatcctagatatagtgttctccatgatgtattac-3' & \\
\hline \multirow[t]{2}{*}{ UM242 } & 5'-CAGCCGCGGCAATGTAAGACGCATCAACGAAGTTATGGGTCGTATT & \\
\hline & GAGATCGTCCTCATTGGGGGCGGCCGCAATCCGCAATACTGCCT-3' & \\
\hline
\end{tabular}

C-terminally his-tagged Mpn140 was expressed under control of the arabinose-inducible $\mathrm{P}_{\text {ara }}$ promoter (plasmid pUM441) for complementation experiments. As seen in Figure 1, mpn140 expression, when induced by the addition of $0.02 \%$ arabinose, completely rescued the growth defect of the orn mutant on plates lacking Atc. A low level of complementation could be seen on plates lacking arabinose (data not shown). Whereas expression of Mpn140 in the presence of $0.02 \%$ or $0.2 \%$ arabinose was detectable on a Coomassie-stained protein gel, we could not detect expression when cultures were grown in the absence of arabinose. We therefore conclude that even low levels of Mpn140 expression were sufficient for $\mathrm{orn}^{-}$ complementation.

Expression of recombinant Rv2837c, on the other hand, when induced from pUM415 by the addition of $0.2 \%$ arabinose, only allowed partial complementation of E. coli $\mathrm{orn}^{-}$ (Table 2). We therefore considered the possibility that (1) Rv2837c needs to be expressed at higher levels than can be achieved from pUM415 or (2) the his-tag might interfere with the activity of this protein. For that reason, we constructed two additional plasmids based on pUC18, a highercopy-number plasmid than pBAD18: pUM417 and pUM428 expressed recombinant C-terminally his-tagged (Rv2837cHis) or native Rv2837c, respectively, under the control of the $\mathrm{P}_{\text {lac }}$ promoter. As seen in Table 2, both constructs

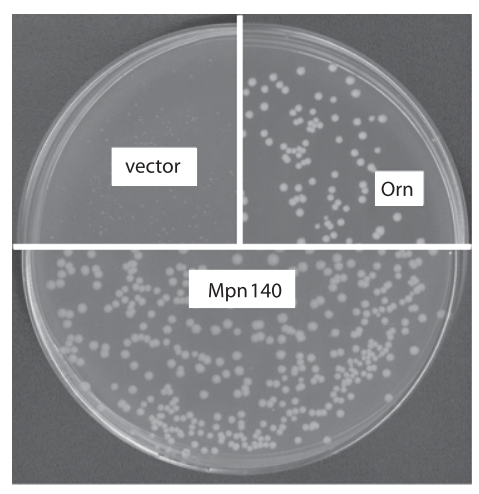

FIGURE 1. Complementation of the conditional orn mutant by expression of Mpn140. Transformants of strain UM341 with pBAD18 (vector control), pUM408 (arabinose-inducible orn) or pUM441 (arabinose-inducible mpn140) were spread on LB plates containing $0.02 \%$ arabinose in the absence of anhydrotetracycline (Atc). 
TABLE 2. Complementation of UM341 (E. coli orn $^{-}$) by the expression of Rv2837c

\begin{tabular}{lcccccc}
\hline & \multicolumn{2}{c}{+ Atc } & & \multicolumn{2}{c}{- Atc } \\
\cline { 2 - 3 } \cline { 5 - 6 } Plasmid & Uninduced & Induced & & Uninduced & Induced \\
\hline pBAD18 (vector) & ++++ & ++++ & & + & + \\
pUM408 (Para Orn-His, Ic) & ++++ & ++++ & & +++ & ++++ \\
pUM415 (P & $P_{\text {ara }}$ Rv2837c-His, lc) & ++++ & ++++ & & + & ++ \\
pUM417 (Plac Rv2837c-His, hc) & +++ & +++ & & +++ & +++ \\
pUM428 (P & Plac Rv2837c, hc) & +++ & +++ & & +++ & +++ \\
\hline
\end{tabular}

Colony sizes are as follows: ++++ , wild type; +++ , slightly smaller; ++ , small; and + , tiny. Atc indicates anhydrotetracycline; Ic, low-copy-number vector; hc, high-copy-number vector. Expression was induced by adding $0.2 \%$ arabinose for $P_{a r a}$ and $1 \mathrm{mM}$ IPTG for $\mathrm{P}_{\text {lac }}$ driven $r v 2837 \mathrm{C}$.

As shown in Figure 3A, Rv2837c was able to degrade nanoRNA 5-mers $\left(5^{\prime} \mathrm{Cy} 5\right.$-CCCCC- $\left.3^{\prime}\right)$ in the presence of manganese. In line with what we had observed previously with NrnA, the degradation pattern produced by $\mathrm{Rv} 2837 \mathrm{c}$ differed from those seen in the Orncatalyzed reaction. Figure 3, A through C, compares degradation patterns that were produced by Rv2837c, Orn, and NrnA, respectively.

As can be seen from this comparison, both Rv2837c and NrnA produced patterns that lacked one intermediate almost entirely, but it was not the same

allowed complete complementation of E. coli $\mathrm{orn}^{-}$. This complementation was independent of the addition of IPTG. Rv2837c and Rv2837c-His expression levels were similar in the absence or presence of IPTG as judged from Coomassie-stained gels (data not shown). The $\mathrm{P}_{\text {lac }}$ promoter is known to be leaky in the presence of a single chromosomal copy of the LacI repressor since multiple copies of the lac operator on pUC18 titrate out the levels of the repressor.

We conclude that the level of expression from $\mathrm{P}_{\text {ara }}$ in the low-copy-number plasmid pUM415 was too low to allow complementation of E. coli $\mathrm{orn}^{-}$. In addition, these data show that the C-terminal his-tag did not interfere with the activity of Rv2837c.

\section{Purification of recombinant Mpn140 and Rv2837c}

To test in vitro activities of Rv2837c and Mpn140, recombinant proteins were purified by means of their C-terminal histag. Whereas Ni-purification yielded highly pure Mpn140 (Fig. 2A), Rv2837c was not sufficiently pure after this procedure. A second purification step was therefore necessary. Ion-exchange chromatography using Vivapure Q mini spin columns proved to be useful for this purpose. The effects of the two steps employed for the purification of Rv2837c are shown in Figure 2B.

\section{Rv2837c degrades nanoRNA in vitro, with 2-mers being a preferred substrate}

We tested purified recombinant Rv2837c for nanoRNase activity. According to previous observations with NrnA (Mechold et al. 2007), we expected its homologs to degrade nanoRNA in the $3^{\prime}-5^{\prime}$ direction. We therefore used nanoRNA substrates that were $5^{\prime}$-labeled with Cy5 as they should allow intermediate products of degradation to be detected. The activity of Orn we measured on Cy5-labeled oligos (5'Cy5-CCCCC-3') was similar to the number that was published previously for this enzyme using radiolabeled substrates $(0.6 \mathrm{nmol} / \mathrm{min} / \mu \mathrm{g}$ and 1.075 $\mathrm{nmol} / \mathrm{min} / \mu \mathrm{g}$, respectively) (Niyogi and Datta 1975). intermediate that was missing: Whereas there was no 3-mer visible in the NrnA-catalyzed reaction, it was the 2-mer that was missing after degradation by Rv2837c. In the case of NrnA, having considered the possibility that 3 -mers might be a preferred substrate of this enzyme, we indeed found turnover numbers to be 10 -fold higher for 3-mers $\left(5^{\prime} \mathrm{Cy} 5\right.$-CCC-3') than for 5-mers $\left(5^{\prime} \mathrm{Cy} 5\right.$ CCCCC-3'; 1.5 vs. $0.14 \mathrm{pmol} / \mu \mathrm{g} / \mathrm{min}$ ) (Mechold et al. 2007). We therefore decided to compare turnover of 5-mers and 2-mers when degraded by Rv2837c. Figure 3D shows the degradation of the 2-mers ( $\left.5^{\prime} \mathrm{Cy} 5-\mathrm{CC}-3^{\prime}\right)$ catalyzed by $0.16 \mu \mathrm{g}$ enzyme compared with the $6 \mu \mathrm{g}$ enzyme that was used for degradation of the 5-mer (Fig. 3A). Initial linear rates of turnover of the 5-mer or 2-mer substrates when measured as disappearance of the initial substrate only lasted for a very short time (for an example, see Fig. $3 \mathrm{E})$. The turnover rates we calculated are therefore only rough estimates and were between 9 and $28 \mathrm{pmol} / \mu \mathrm{g} / \mathrm{min}$ when we measured the disappearance of 5 -mers and were between 160 and $200 \mathrm{pmol} / \mu \mathrm{g} / \mathrm{min}$ when we measured the disappearance of 2-mers. We conclude that the turnover
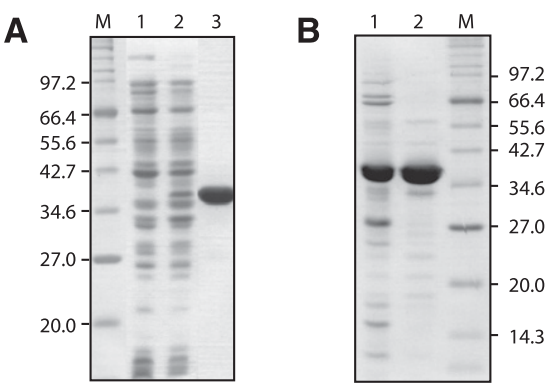

FIGURE 2. Purification of recombinant Mpn140 (A) and Rv2837c (B). Samples were separated on $12 \%$ Tris-Glycine-SDS PA-gels followed by staining with BioSafe colloidal Coomassie stain (Bio-Rad). $\mathrm{M}$ indicates marker. (A) Total protein extract of cultures of MG1655 carrying pUM441 grown in the absence (lane 1) or presence (lane 2) of $0.2 \%$ arabinose; (lane 3) $6 \mu \mathrm{g}$ of purified Mpn140 after elution from Niagarose. (B) $5 \mu \mathrm{g}$ of purified Rv2837c after one step (lane 1) or two purification steps (lane 2) using Ni-agarose affinity chromatography followed by ion exchange chromatography on Vivapure Q. 

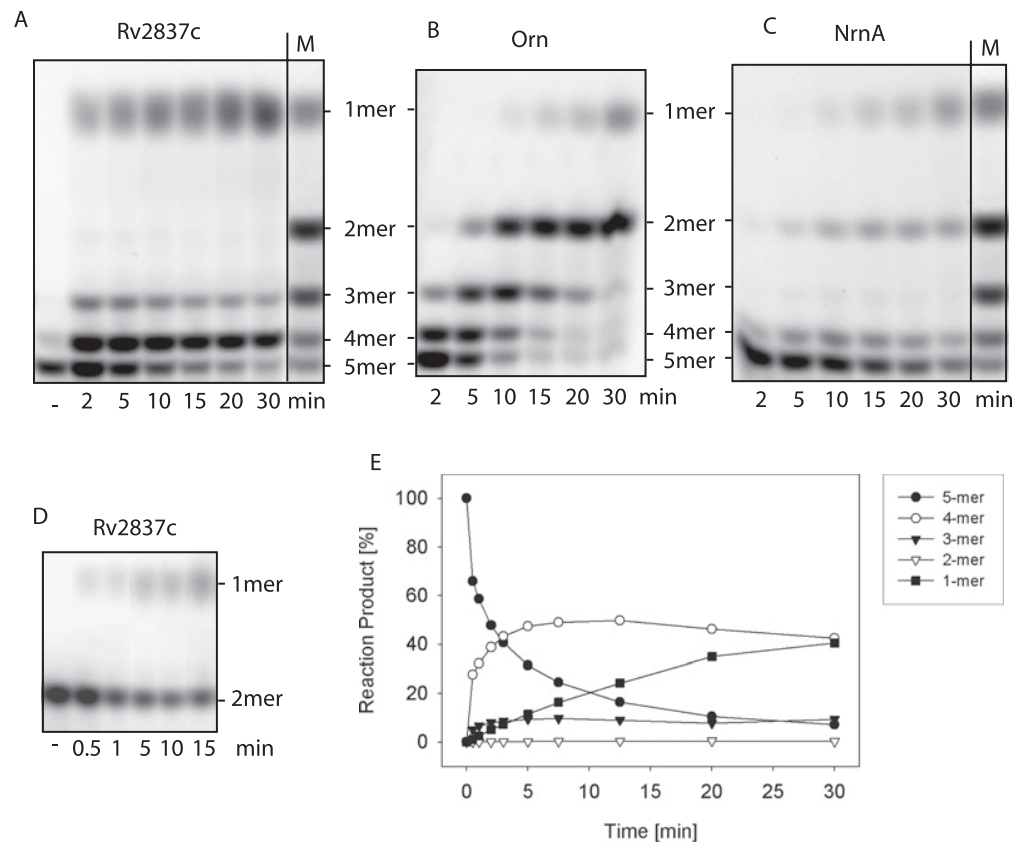

FIGURE 3. Comparison of Rv2837c- $(A)$, Orn- $(B)$, and NrnA- $(C)$ catalyzed degradation of 5 -mer nanoRNAs. Shown is the separation of reaction products on 22\% PA-gels. The reverse migration can be accounted for by the fact that cyanine dyes have a lower net negative charge than nucleic acids: Thus, removing nucleotides will reduce the charge relative to the mass of the oligonucleotide and cause it to shift up instead of down. Reactions contained $6 \mu \mathrm{g} \mathrm{Rv} 2837 \mathrm{c}$ $(A), 0.07 \mu \mathrm{g}$ Orn $(B)$, or $9 \mu \mathrm{g} \operatorname{NrnA}(C)$, and $5.3 \mu \mathrm{M}, 2.8 \mu \mathrm{M}$, or $3 \mu \mathrm{M}$ 5-mer RNA (5'Cy5CCCCC- $\left.3^{\prime}\right)$, respectively. Reaction $D$ contained $0.16 \mu \mathrm{g}$ Rv2837c and $5.4 \mu \mathrm{M} 2$-mer RNA $\left(5^{\prime} \mathrm{Cy} 5-\mathrm{CC}-3^{\prime}\right)$. The minus indicates a control lacking enzyme. $\mathrm{M}$ indicates a size marker obtained by an Orn-catalyzed reaction. (E) Quantification of reaction products and degradation intermediates of 5'Cy5-CCCCC-3' (at $5.4 \mu \mathrm{M}$ ) by $7.8 \mu \mathrm{g}$ Rv2837c. Closed circles indicate 5-mers; open circles, 4-mers; closed triangles, 3-mers; open triangles, 2-mers; and squares, 1-mers.

of 2-mers was between five- and 10 -fold faster than that of 5-mers when measured as disappearance of initial substrate.

On the other hand, the appearance of the final product monomer arising from the degradation of 5-mers could be measured more accurately (for an example, see Fig. 3E). Measured in this way, the rate was $1 \mathrm{pmol} / \mathrm{min} / \mu \mathrm{g}$ for the degradation of 5 -mer into monomer and $2 \mathrm{pmol} / \mathrm{min} / \mu \mathrm{g}$ for the degradation of 3-mers $\left(5^{\prime} \mathrm{Cy} 5-\mathrm{CCC}-3^{\prime}\right)$ into monomer by Rv2837c. The rate of conversion of 2-mers into monomers corresponds to the disappearance-of-substrate turnover rate as there are no more intermediate degradation products. This rate was found to be between 160 and $200 \mathrm{pmol} / \mathrm{min} / \mu \mathrm{g}$, which was two orders of magnitude faster than that of 5-mers and 3-mers. This suggests that the degradation of the 2-mer is the fastest step in the degradation of longer substrates (5-mers and 3-mers) and that 2-mers are a preferred substrate of Rv2837c.

\section{Mpn140 degrades nanoRNA in vitro}

Initial in vitro experiments with Mpn140 were designed to optimize reaction conditions for the Mpn140-catalyzed deg- radation of nanoRNA. These experiments were performed on a 5-mer nanoRNA (5'Cy5-CCCCC- $\left.3^{\prime}\right)$. Among the buffers we tested, Mpn140 activity was highest in HEPES ( $\mathrm{pH}$ 7.0). Other buffers tested were HEPES ( $\mathrm{pH} 7.5)$, Tris $(\mathrm{pH} 6.8, \mathrm{pH}$ 7.5, and $\mathrm{pH} 8.0$ ), and BIS-TRIS propane $(\mathrm{pH} 9.0)$. Activities in these buffers were $81 \%, 36 \%, 30 \%, 23 \%$, and $22 \%$, respectively, of the activity measured in HEPES ( $\mathrm{pH}$ 7.0). Among the metal ions tested, $\mathrm{Co}^{2+}$ allowed the highest turnover of $5^{\prime} \mathrm{Cy} 5$-CCCCC-3', followed by $\mathrm{Mn}^{2+}$, with $69 \%$ activity compared to $\mathrm{Co}^{2+}$. The activity in the presence of $\mathrm{Fe}^{2+}$ was $58 \%$ that of $\mathrm{Co}^{2+}$, followed by $\mathrm{Ca}^{2+}$ and $\mathrm{Mg}^{2+}$ with considerably lower values ( $24 \%$ and $20 \%$, respectively). Subsequent experiments were therefore performed in HEPES buffer ( $\mathrm{pH} 7.0$ ), in the presence of $\mathrm{Co}^{2+}$. Figure $4 \mathrm{~A}$ shows the degradation of the 5-mer nanoRNA (5'Cy5-CCCCC-3') by Mpn140. Only small amounts of intermediate degradation products accumulated during the degradation of this substrate.

As opposed to the degradation of 5-mers (Fig. 4A) and 4-mers (Fig. 4B), the degradation of a 3-mer nanoRNA $\left(5^{\prime} \mathrm{Cy} 5-\mathrm{CCC}-3^{\prime}\right)$ produced appreciable amounts of intermediates with the length of a 2-mer (Fig. 4C). We compared the activity of Mpn140 on substrates with lengths varying between 2 and 5 nucleotides (nt). The overall tendency was a decrease of activity with decreasing chain length. We also included one nanoRNA substrate of different sequence, a 3-mer that contained As ( $5^{\prime}$ Cy5-AAA-3'). Activity on the 3-mer nanoRNA containing As was comparable to that on 3-mer containing Cs.

As NrnB (Fang et al. 2009) and Orn (Mechold et al. 2006) nanoRNases were active on DNA substrates of short lengths, we tested Mpn140's activity on 3-mer oligo DNAs (5'Cy5-CCC-3'). Mpn140 was found to degrade DNA 3-mers with an activity of a similar order of magnitude compared with that seen with nanoRNA. In this context, we also tested NrnA for activity on the DNA 3-mer and found this nanoRNase to be active on this substrate as well (data not shown).

\section{Activity of Mpn140 and Rv2837c on a 24-mer RNA}

We also asked whether Mpn140 and Rv2837c could degrade longer RNAs, in particular a 24-mer (5'-CACACA CACACACACACACACACA-3') that was $5^{\prime}$-end labeled with ${ }^{33} \mathrm{P}$. Mpn140 and Rv2837c both showed activity on this 

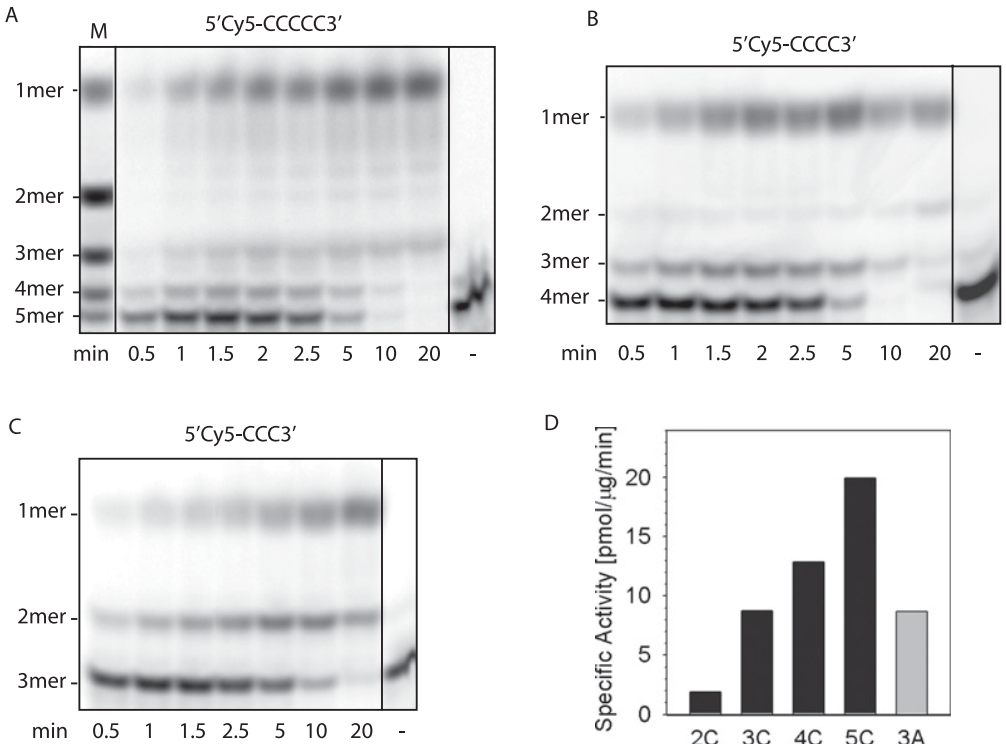

D

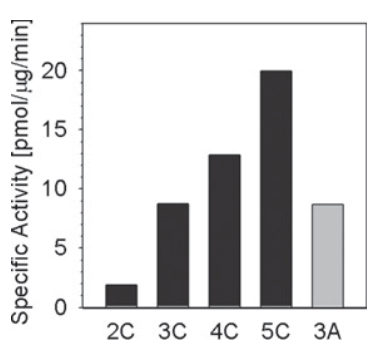

FIGURE 4. Mpn140-catalyzed degradation of nanoRNA. Shown is the separation of reaction products on $22 \%$ PAA gels $(A-C)$. Forty microliter reactions contained $5.8 \mu \mathrm{g}$ Mpn140 and 6.0 $\mu \mathrm{M}$ RNA (5'Cy5-CCCCC-3' for $A, 5^{\prime} \mathrm{Cy} 5-\mathrm{CCCC}-3^{\prime}$ for $B$, and $5^{\prime} \mathrm{Cy} 5-\mathrm{CCC}-3^{\prime}$ for $C$ ). The minus indicates controls lacking enzyme. $(D)$ Comparison of initial rates of degradation of 5'Cy5-CCCCC-3' (5C), 5'Cy5-CCCC-3' (4C), 5'Cy5-CCC-3' (3C), 5'Cy5-CC-3' (2C), and $5^{\prime} \mathrm{Cy} 5-\mathrm{AAA}-3^{\prime}(3 \mathrm{~A})$. Specific activities were measured as disappearance of substrate in three independent experiments and averaged $( \pm \mathrm{SE})$.

substrate. Rv2837c degraded the 24-mer to near completion after 30 min (Fig. 5A).

We decided to study this activity of Mpn140 in more detail. We tested the degradation of the 24-mer by Mpn 140 in the presence of $\mathrm{Mn}^{2+}$ or $\mathrm{Co}^{2+}$. The activity in the presence of $\mathrm{Mn}^{2+}$ was $\sim 62 \%$ of that measured in reactions containing $\mathrm{Co}^{2+}$ (data not shown). Figure 5B shows the time course of degradation of the 24-mer by Mpn140 in the presence of $\mathrm{Co}^{2+}$. Since this activity could potentially also arise from impurities in the protein preparation, we created a mutant enzyme to determine whether the activity on the 24-mer was inherent to Mpn140. In this mutant enzyme, Asp118, His119, and His120, the three amino acids representing a part of motif III that defines the DHH protein family, were replaced by alanines. A similar triple mutation in $\mathrm{NrnB}$ (NrnB-DHH) largely inactivated this protein (Fang et al. 2009).

Mpn140-DHH, exactly like NrnB-DHH, was unable to complement E. coli orn ${ }^{-}$(UM341) and showed only marginal activity $(<1 \%)$ on 5 -mer nanoRNAs (data not shown). The activity of Mpn140-DHH on the 24-mer was estimated to be $\sim 15 \%$ of Mpn140 (Fig. 5B). We concluded that the activity of Mpn140 observed on the 24mer was inherent to the protein and not caused by impurities in the protein preparation. The activity we measured for Mpn140 on the $24-\mathrm{mer}$ was $0.01 \mathrm{pmol} / \mathrm{min} /$ $\mu \mathrm{g}$. This number shows that similar to NrnA and NrnB, Mpn140 strongly prefers nanoRNA over longer RNA substrates.

\section{Rv2837c and Mpn140 complement an E. coli cys $Q^{-}$mutant}

In addition to its ability to degrade nanoRNA, NrnA acts as a pAp-phosphatase. We therefore tested Rv2837c and Mpn140 for their ability to complement a mutant in $c y s Q$, the pAp-phosphatase of $E$. coli. The $c y s Q$ mutant phenotype manifests itself in a growth defect in the absence of cysteine. This phenotype depends on the particular E. coli strain used and can be rather leaky, allowing residual growth (Neuwald et al. 1992). We transformed plasmids expressing Rv2837c or Mpn140 into our cys $Q$ deletion strain UM285. In the absence of arabinose, Mpn140 expressed from pUM441 formed colonies that were slightly bigger than that of the vector control (pBAD18), suggesting some partial complementation of cys $Q^{-}$even in the absence of induction. Colonies formed by pUM415 expressing Rv2837c were identical to those of the vector control, suggesting a lack of complementation without induction. On the other hand, pUM404, a control plasmid expressing cysQ, allowed complete complementation even in the absence of arabinose, since colonies grown on plates with or without cysteine were of similar size. Transformants of the $c y s Q$ deletion strain (UM285) with pUM417 or pUM428, the two plasmids that expressed Rv2837c under the control of $\mathrm{P}_{\text {lac }}$ from a higher-copy-number plasmid, also formed colonies of similar size on plates irrespective of the presence of cysteine or IPTG—in fact, in this case colonies were slightly bigger on plates lacking cysteine (data not shown). We next compared growth in liquid medium in the presence or absence of cysteine and at different concentrations of arabinose. Table 3 shows doubling times obtained during logarithmic growth of strain UM285 $(\Delta c y s Q)$ containing control
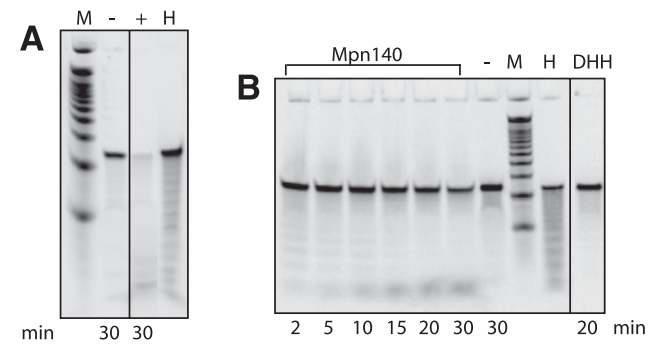

FIGURE 5. Activity of Rv2837c (A) and Mpn140 (B) on 24-mer RNA. Reactions containing $5^{\prime}{ }^{33} \mathrm{P}$-labeled 24-mer RNA (5'-CACA CACACACACACACACACACA-3') and $3 \mu \mathrm{g} \operatorname{Rv} 2837 \mathrm{c}$ (+ in panel A) or $6 \mu \mathrm{g} \mathrm{Mpn} 140(B)$ in the presence of $\mathrm{Mn}^{2+}$ or $\mathrm{Co}^{2+}$, respectively. M indicates decade marker; $\mathrm{H}$, alkaline hydrolysis control; and $\mathrm{DHH}$, reaction contained $6 \mu \mathrm{g}$ Mpn140-DHH. 
TABLE 3. Complementation of UM285 (E. coli cys $Q^{-}$) by the expression of Rv2837c or Mpn 140 from different plasmids

\begin{tabular}{|c|c|c|c|c|c|c|c|c|c|c|}
\hline \multirow[b]{2}{*}{ Plasmid } & \multicolumn{2}{|c|}{-ara } & \multicolumn{2}{|c|}{$0.02 \%$ ara } & \multicolumn{2}{|c|}{$0.05 \%$ ara } & \multicolumn{2}{|c|}{$0.1 \%$ ara } & \multicolumn{2}{|c|}{$0.2 \%$ ara } \\
\hline & -Cys & + Cys & -Cys & +Cys & -Cys & + Cys & -Cys & + Cys & -Cys & + Cys \\
\hline pBAD18 (vector) & 175 & 92 & 178 & 92 & - & - & - & - & - & - \\
\hline pUM404 (P ara CysQ-His, Ic) & 92 & 94 & 94 & 100 & - & - & - & - & - & - \\
\hline pUM415 (P ${ }_{\text {ara }}$ Rv2837c-His, Ic) & 173 & 92 & 118 & 94 & 104 & 97 & 99 & 102 & 98 & 105 \\
\hline pUM417 (P lac Rv2837c-His, hc) & 177 & 209 & - & - & - & - & - & - & - & - \\
\hline pUM428 (P ${ }_{\text {lac }}$ Rv2837c, hc) & 179 & 208 & - & - & - & - & - & - & - & - \\
\hline pUM441 (Para Mpn140-His, Ic) & 127 & 95 & 91 & 98 & - & - & - & - & - & - \\
\hline
\end{tabular}

Numbers indicate doubling times in minutes that were calculated from the slopes of the growth curves during exponential growth. - indicates not determined; hc, high copy; and lc, low copy.

plasmids or plasmids expressing Mpn140 or Rv2837c. The observed doubling times correlated well with the observed colony size on plates. Doubling times of the $c y s Q$ mutant strain containing the vector control were nearly twice as long in cultures that were grown in the absence of cysteine compared with those that were grown in its presence (172 vs. 92 $\mathrm{min}$ ), consistent with the $c y s Q$ mutant phenotype. Similar doubling times of cultures that were grown in the absence or presence of cysteine indicate complementation of the $c y s Q$ mutant phenotype. As can be seen from these data, different concentrations of arabinose were necessary for complete complementation of the growth defect of UM285 (E. coli $\left.c y s Q^{-}\right)$when using different expression plasmids. Whereas the control plasmid expressing CysQ did allow complementation even in the absence of arabinose, pUM441 expressing Mpn140 allowed complete complementation at $0.02 \%$ arabinose. pUM415 expressing Rv2837c required the addition of $0.05 \%-0.1 \%$ for complete complementation of the $c y s Q^{-}$ strain. Table 3 also shows that growth was faster in the absence of cysteine than in its presence when proteins were expressed at higher levels. Potential explanations for this observation are discussed below. Figure 6 shows growth curves in the presence of arabinose at those concentrations that allowed complementation of E. coli $c y s Q^{-}$.

\section{Rv2837c and Mpn140 dephosphorylate pAp in vitro}

Recombinant Rv2837c and Mpn140 were tested for their ability to dephosphorylate pAp to AMP in vitro. Both enzymes were able to convert pAp to AMP. The turnover of pAp to AMP by Rv2837c in the presence of manganese was estimated to be $1 \mathrm{nmol} / \mathrm{min} / \mu \mathrm{g}$. In contrast, we were unable to observe any pAp-phosphatase activity by Mpn140 in the presence of manganese, but we could detect such activity in the presence of cobalt, with a turnover of $\sim 600$ $\mathrm{pmol} / \mathrm{min} / \mu \mathrm{g}$, as well as, to a lesser extent, in the presence of magnesium. Since our method of measuring the dephosphorylation of pAp is not very sensitive, potential pApphosphatase activities of Mpn140 in the presence of manganese might have been below our detection limit.

\section{SMU.1297, the NrnA homolog from Streptococcus mutans is also bifunctional}

SMU.1297 is the BLAST bidirectional best hit of NrnA in $S$. mutans. This protein was previously identified in a screen for proteins that confer resistance to superoxide stress in this organism. SMU.1297 was shown to have pAp-phosphatase activity in vitro and to rescue an E. coli cys $Q$ mutant when expressed from a plasmid (Zhang and Biswas 2009). However, nanoRNase activity could not be detected in vitro in that study. To a large extent, measuring any activity in vitro is sensitive to the specific conditions used. Undetectable activity could be due to the failure to find conditions that support activity. In contrast, our in vivo complementation assay allows the detection of nanoRNase activity in an efficient and reliable way. We therefore decided to test the ability of
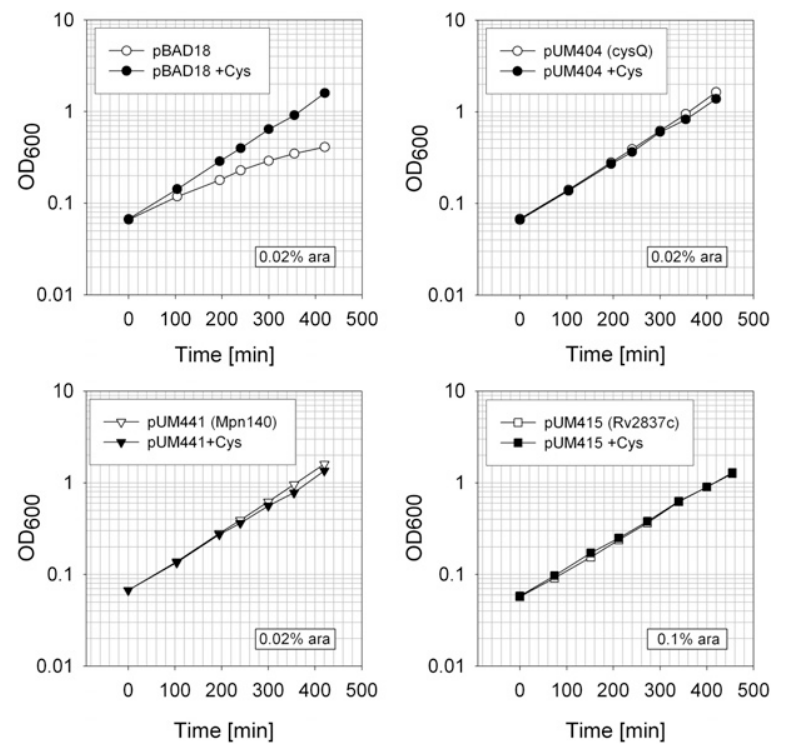

FIGURE 6. Complementation of the E. coli cysQ mutant by the expression of Mpn140 or Rv2837c. Shown is the growth of strain UM285 carrying the indicated plasmids in MOPS-medium containing $0.4 \%$ glycerol and arabinose at the indicated concentration, in presence or absence of $40 \mu \mathrm{g} / \mathrm{mL}$ cysteine as indicated. 
SMU.1297 to complement the absence of E. coli Orn in order to determine whether SMU.1297 differs from NrnA and the NrnA homologs studied here, in lacking nanoRNase activity. To this end, we transformed our E. coli orn mutant (UM341) with two different plasmids expressing SMU.1297: (1) pIB1297, an EmR shuttle plasmid derived from pOri23, which expressed SMU.1297 from its native promoter, and (2) pIB900, a plasmid based on pASK-IBA43plus, which expressed recombinant his-tagged SMU.1297.

As expected, transformants of UM341 with the vector controls pOri23 or pASK-IBA43plus did not produce colonies on LB-plates lacking Atc but did produce colonies on plates supplemented with Atc (Table 4). However, plasmids expressing SMU.1297 (pIB1297 and pIB900) did allow the formation of colonies on plates lacking Atc when transformed into UM341.

Transformants of UM341 with pIB1297 or the corresponding vector control pOri23 produced heterogeneous colonies. Nevertheless, there was no difference between colony sizes produced by UM341 carrying pIB1297 on plates with or without Atc (Table 4), indicating complementation of the orn mutant phenotype by expression of SMU.1297 from pIB1297.

pIB900 expressed recombinant SMU.1297 under the control of the Atc-inducible tet-promoter. Therefore, it was not possible to add Atc in order to trigger high expression of SMU.1297, as this would have allowed expression of orn from the chromosome at the same time. Nonetheless, colonies formed by transformants of UM341 with pIB900 in the absence of Atc were similar in size to colonies that were grown in the presence of Atc.

We conclude that expression of SMU.1297 can complement the E. coli orn ${ }^{-}$mutant, indicating nanoRNase activity of the streptococcal NrnA homolog in vivo in E. coli.

\section{DISCUSSION}

NanoRNases are essential components for the maintenance of cells. Unexpectedly, we discovered previously that this role

TABLE 4. Complementation of UM341 (E. coli orn') by the expression of SMU.1297

\begin{tabular}{|c|c|c|}
\hline Plasmid & + Atc & - Atc \\
\hline pBAD18 (vector) & ++++ & + \\
\hline pUM408 (Para Orn-His, Ic) & ++++ & ++++ \\
\hline pOri23 (vector) & $++^{\mathrm{a}}$ & - \\
\hline plB1297 (SMU.1297) & $++^{a}$ & $++^{\mathrm{a}}$ \\
\hline pASK-IBA43plus (vector) & ++++ & - \\
\hline plB900 $\left(\mathrm{P}_{\text {tet }}\right.$ His-SMU.1297) & ++++ & ++++ \\
\hline
\end{tabular}

Colony sizes are as follows: ++++, as wild type (CF 10230); ++, small; +, tiny; and - , no growth. Atc indicates anhydrotetracycline. Orn is under control of the Atc-inducible $\mathrm{P}_{\text {LtetO-1 }}$ promoter in UM341. Atc addition leads to the expression of the chromosomal Orn and consequently results in colony sizes that are similar to that produced by the corresponding wild type.

${ }^{a}$ Heterogeneous colony sizes. The smaller and heterogeneous colonies seemed to be specific to pOri23, an E. coli/L. lactis shuttle vector that confers resistance to erythromycin. in disposing of RNA fragments was systematically associated with another housekeeping activity, linked to sulfur assimilation, within the same proteins. We conducted the present study in order to determine whether such bifunctionality is a common trait of NrnA-homologous proteins.

We studied the NrnA homolog from M. tuberculosis and, in more detail, the NrnA homolog of M. pneumoniae, and found that the two proteins are bifunctional and have both nanoRNase and pAp-phosphatase activity in vitro as well as in vivo. We also show proof for bifunctionality of SMU.1297, the NrnA homolog from S. mutans, by showing the ability of this protein to complement a conditional mutant of E. coli orn. This protein was previously shown to have pAp-phosphatase activity, but activity on nanoRNA could not be detected in vitro (Zhang and Biswas 2009).

NrnA, Rv2837c, and Mpn140 show more or less strong preferences for specific nanoRNA substrate lengths. Whereas NrnA prefers RNA 3-mers with a 10-fold higher specific activity as compared to 5-mers, Rv2837c shows a preference for nanoRNA of a different length, namely, 2-mers. Mpn140 degrades nanoRNA in vitro with activities varying within one order of magnitude as follows: 5-mer $>4$-mer $>3$ mer $>2$-mer. These preferences could reflect adaptations to the different sets of RNases present in a given organism, which in turn could affect the overall size distribution of nanoRNAs in the cell. In addition, the potential presence of additional nanoRNases with different preferences could complement the nanoRNase activity of NrnA homologs. Whereas the presence of RNases in M. pneumoniae seems to resemble mainly those of $B$. subtilis, the repertoire of RNases present in M. tuberculosis has partial similarity to both B. subtilis and E. coli (Supplemental Table S1). The bacterial species we chose differ from $E$. coli regarding their sulfur metabolism. In M. tuberculosis, adenosine $5^{\prime}$-phosphosulfate (APS) can be directly reduced to sulfite by APS reductase (Williams et al. 2002), thus bypassing the requirement for phosphoadenosine $5^{\prime}$-phosphosulfate (PAPS) in the synthesis of cysteine. However, the presence of PAPS-dependent sulfotransferases in M. tuberculosis allows the production of sulfated metabolites, some of which have been implicated in its pathogenesis (for reviews, see Schelle and Bertozzi 2006; Bhave et al. 2007). Furthermore $M$. tuberculosis codes for ACPs both for fatty acid and polyketide biosynthesis, which become functional upon 4-phosphopantetheine transfer from coenzyme A, generating $\mathrm{pAp}$.

M. tuberculosis does harbor a cysQ ortholog, Rv2131c. The pAp-phosphatase activity of this protein was recently documented in vitro as well as in vivo through its ability to complement a cysQ mutant of E. coli (Hatzios et al. 2008). $M$. tuberculosis also has an Orn ortholog. To our knowledge, the functionality of this protein, Rv2511, has not yet been verified by biochemical or complementation studies. However, like Orn from E. coli and human Orn/Sfn, the Orn homolog of 
Mycobacterium smegmatis was shown to hydrolyze the $5^{\prime}$ p-nitrophenyl ester of TMP in vitro in a spectrophotometric assay developed to measure Orn-like activity (Young Park et al. 2008). Analyzing the phylogenetic distribution of NrnA, we previously showed that most bacterial species that have NrnA have neither CysQ nor Orn. M. tuberculosis is one of the few exceptions, having orthologs of NrnA, Orn, and CysQ. Other examples that have all three orthologs can be found among Actinobacteria (Mechold et al. 2007). However, there are also species in this class of bacteria, such as in the genus Streptomyces, that have only Orn (or Orn and CysQ) and do not have NrnA. We show here that, like NrnA, Rv2837c, the NrnA homolog of M. tuberculosis, is bifunctional and has Orn-like as well as CysQ-like activity. The apparent redundancy of these activities cannot currently be explained.

Reduced sulfur-containing metabolites are an important element of bacterial antioxidant defense systems. In agreement with this, the expression of mycobacterial genes involved in reductive sulfate assimilation is induced by oxidative stress and within the environment of the macrophage of infected lung tissue (for review, see Bhave et al. 2007). This likely causes increase in both the flux through the sulfate assimilation pathway and in the subsequent production of pAp. Furthermore, synthesis of fatty acids and possibly polyketides is essential for the long-term survival of $M$. tuberculosis. Having two enzymes that hydrolyze pAp could therefore be advantageous. In addition, the two enzymes dephosphorylating pAp might be transcribed or activated under specific conditions. Consistent with this idea, it has been shown that in clinical samples of infected lung tissue from Tuberculosis patients, Rv2837c is 3.2-fold or sevenfold up-regulated in granulomatous or extragranulomatous lung tissue, respectively, as compared to bacteria cultured in the laboratory (Rachman et al. 2006).

All plasmids that expressed proteins with pAp-phosphatase activity (CysQ, Rv2837c, and Mpn140) at high levels caused a slowdown of growth of the E. coli cysQ mutant in the presence of cysteine as compared to its absence. This opens up the possibility that elevated pAp-phosphatase activity levels could be detrimental under conditions when not much pAp is expected to accumulate. Cysteine represses the sulfur assimilation pathway and hence the synthesis of pAp (Daßler et al. 2000). We have two possible explanations for this phenomenon: (1) in the absence of pAp, pAp-phosphatase might act on nonphysiological substrates, which might be needed for optimal growth, and (2) a minimum amount of pAp is needed to support optimal growth.

Apparent redundancy of nanoRNase activity, arising from the presence of this activity in Orn and Rv2837c in $M$. tuberculosis, could indicate more specific roles for the two enzymes. We had pointed out before that NrnA might play a role in the degradation of $\mathrm{pGpG}$, a linear dinucleotide resulting from the degradation of cyclic di-GMP by phosphodiesterase. Cyclic di-GMP was shown to play an important role in the long-term survival of $M$. smegmatis (Kumar and
Chatterji 2008), a faster-growing, nonpathogenic species that is commonly used as model system for pathogenic mycobacterial pathogens. The preference of Rv2837c for 2-mers is in agreement with a potential role for this enzyme in the degradation of pGpG.

Unlike M. tuberculosis, M. pneumoniae does not have Orn or CysQ homologs. M. pneumoniae is unable to synthesize cysteine from sulfate (Yus et al. 2009). However, pAp is generated from Coenzyme A during the activation of ACP (Mpn406/AcpA) by transferring the 4-phosphopantetheine moiety of Coenzyme A catalyzed by Mpn298 (AcpS) (Yus et al. 2009). This generates the need for an enzyme to hydrolyze pAp. In reference to the eukaryotic enzyme, this activity was termed BPNT (standing for $3^{\prime}\left(2^{\prime}\right), 5^{\prime}$ bisphosphate nucleotidase) (Yus et al. 2009), but this activity was not associated with a protein. We show here that Mpn140 can perform this function.

Among the limited number of RNases (RNase P, III, J1, and R) that have been annotated in the genome of $M$. pneumoniae is an RNase J1 homolog. We had shown that the RNase J1 homolog from B. subtilis can degrade nanoRNA in vitro and partially complements our conditional E. coli orn mutant (Fang et al. 2009). However, nanoRNA might not be a preferred substrate for RNase J1, and despite the ability of this enzyme to finish degradation once started on a longer substrate, it is not clear whether or not it might degrade 2- to 5 -mers that arise from incomplete degradation catalyzed by other enzymes. The nanoRNase activity of Mpn140 might therefore be essential. In agreement with this conjecture, global transposon mutagenesis aiming to identify essential genes in M. pneumoniae and Mycoplasma genitalium failed to identify insertions in mpn140 or the nrnA homolog of $M$. genitalium, $m g 371$, suggesting that these genes are essential (Hutchison et al. 1999; Glass et al. 2006).

Multifunctional enzymes are more frequent among the proteins coded in the minimal genome of $M$. pneumoniae as compared to more complex bacteria (Yus et al. 2009). A large-scale identification of protein complexes in $M$. pneumoniae using tandem affinity-mass spectrometry identified Mpn140 as part of a complex containing proteins Mpn148, Mpn450, Mpn311, Mpn246, Mpn011, and Mpn466 in the core complex and Mpn204, Mpn245, Mpn419, and Mpn095 as attachments (Kühner et al. 2009). Most of the proteins in this complex are of unknown function, as is the complex itself. According to annotations in UniProt or KEGG, the putative activity of some of these proteins points (1) to association with the cell membrane-Mpn011 and Mpn466 are uncharacterized lipoproteins, Mpn311 is an adhesinrelated protein (Schmidl et al. 2010), and Mpn095 is an amino acid permease; (2) to the metabolism of DNA and nucleotides-Mpn246 is a guanylate kinase and Mpn450 is annotated as DNA polymerase III subunit delta; and (3) to protein synthesis-Mpn245 is annotated as peptide deformylase and Mpn419 is a alanyl-tRNA synthase (Kühner et al. 2009). Assuming the physical interactions of these 
proteins have physiological relevance, we may speculate that Mpn140 might have yet another activity independent from its activity on nanoRNA and pAp. This activity might be related to the ability to degrade DNA. The association of these proteins could be a degradative complex similar to the degradosome (Danchin 2009).

Mpn140-catalyzed degradation of nanoRNA 5-mers yielded only small amounts of intermediate degradation products (4-mers, 3-mers, and 2-mers). This enzyme degrades substrates of shorter lengths less efficiently: In fact, its activity seems to decline with substrate length. The low amounts of intermediates thus cannot be explained by different turnover numbers for substrates of different lengths. Intermediates could become visible if the enzyme releases them instead of degrading them to completion, a characteristic of nonprocessivity. A complete lack of intermediates, on the other hand, could be produced either by a processive enzyme or by an enzyme that degrades with opposite polarity, from $5^{\prime}$ to $3^{\prime}$. Since we clearly saw intermediates in the degradation of shorter substrates (4-mers or 3-mers), $5^{\prime}$ to $3^{\prime}$-directed degradation can be largely excluded. Moreover, when using a $5^{\prime}{ }^{33}$ P-labeled 24 -mer RNA substrate, degradation intermediates were clearly visible, confirming a $3^{\prime}-5^{\prime}$ exonuclease activity. However, it has been published recently that Mpn140 has an in vitro 5'-3' exonuclease activity on 6-mers and 11-mers oligos (Wakamatsu et al. 2011). The corresponding specific activities are in the same range as those reported here for the $3^{\prime}-5^{\prime}$ degradation of Cy5labeled nanoRNAs, raising the possibility that Mpn140 may change its polarity with the nature of the substrate.

\section{MATERIALS AND METHODS}

\section{Strains, plasmids, and growth conditions}

E. coli strains were grown at $30^{\circ} \mathrm{C}$ in LB or in MOPS-minimal medium (Neidhardt et al. 1974) containing $40 \mu \mathrm{g} / \mathrm{mL}$ amino acids where indicated, K-phosphate at $2 \mathrm{mM}$, vitamin B1 at $0.0005 \%$, glycerol at $0.4 \%$. Arabinose or IPTG was present for induction of the $\mathrm{P}_{\text {ara }}$ or $\mathrm{P}_{\text {lac }}$ promoter, respectively, as indicated. Atc was added at $250 \mathrm{ng} / \mathrm{mL}$ for the induction of $\mathrm{P}_{\text {LtetO-1 }}$. Ampicillin $(100 \mu \mathrm{g} /$ $\mathrm{mL})$, kanamycin $(25 \mu \mathrm{g} / \mathrm{mL})$, or erythromycin $(200 \mu \mathrm{g} / \mathrm{mL})$ was added for plasmid maintenance or to select for chromosomal markers.

Strains, plasmids, and primers used in this study are listed in Table 1. The plasmid for expression of his-tagged Rv2837c under the control of the $\mathrm{P}_{\text {ara }}$ promoter (pUM415) was constructed as follows: primers UM181 and UM182 were used for PCR amplification of $r v 2837 c$ from $M$. tuberculosis H37Rv chromosomal DNA. The EcoRI- and XhoI-digested fragment was used to replace the CDS from pUM407, leaving the regions coding for the C-terminal his-tag and the ribosomal binding site intact. In order to obtain higher expression levels of Rv2837c, we amplified $r v 2837 c$ —including the region coding for the C-terminal his-tag-from pUM415 using primers UM192 and UM193 and inserted the EcoRI/XbaI-digested PCR fragment into pUC18 digested with EcoRI and XbaI, thus creating pUM417. pUM428 expresses native Rv2837c under the control of the $\mathrm{P}_{\text {lac }}$ promoter and was created by PCR amplification of $r v 2837 c$ from pUM415 using primers UM192 and UM199, followed by insertion of the EcoRI/SphI-digested fragment into pUC18 digested with EcoRI and SphI. pUM441 expresses C-terminally histagged Mpn140 and was constructed as follows: mpn140 was PCR amplified from chromosomal DNA of M. pneumoniae M129 using primers UM212 and UM213. The NheI/XhoI-digested PCR fragment was used to replace the CDS of pUM407 digested by NheI and XhoI, thus creating pUM438. Due to the alternate genetic code used in Mycoplasma, mpn140 contains two UGA codons that code for tryptophan in the host organism but represent opal stop codons when expressed in E. coli. These UGA codons were replaced by UGG by means of overlapping PCR. Two PCR fragments were amplified using pUM438 as a template: PCR 1 and PCR 2 were obtained with primers UM212 and UM231 or with UM229 and UM234, respectively. The outside primers UM212 and UM234 and equimolar amounts of PCR fragments 1 and 2 were used to perform overlapping PCR. The PCR fragment thus obtained was digested with NheI and SacI and used to replace the corresponding fragment in pUM438, creating pUM441.

For the construction of pGP1, expressing recombinant Mpn140$\mathrm{DHH}$ mutant protein with alanine replacements of amino acids D118, H119, and H120, we replaced the 408-bp NheI/KspI fragment of pUM441 by a PCR fragment that was amplified using primers UM212 and UM242, with pUM441 as template.

\section{Purification of his-tagged proteins and activity assays}

Recombinant Mpn140 was Ni-affinity purified as described previously (Mechold et al. 2006) from $300 \mathrm{~mL}$ cultures of MG1655 carrying pUM441 grown in $\mathrm{LB}$ at $30^{\circ} \mathrm{C}$. Expression was induced at an OD600 of 0.7 by the addition of $0.2 \%$ arabinose for $2 \mathrm{~h}$. Recombinant Rv2837c was expressed in $1 \mathrm{~L}$ cultures of MG1655 carrying pUM417. Ni-agarose purification was performed by batch purification on $2 \mathrm{~mL} \mathrm{Ni-agarose} \mathrm{(Qiagen),} \mathrm{essentially} \mathrm{as} \mathrm{described} \mathrm{pre-}$ viously (Mechold et al. 2006). Elution was accomplished by adding seven aliquots of $1.5 \mathrm{~mL}$ elution buffer $(250 \mathrm{mM}$ imidazole, $50 \mathrm{mM}$ Na-phosphate at pH 8.0, $300 \mathrm{mM} \mathrm{NaCl}, 0.4 \mathrm{mM}$ phenylmethylsulfonyl fluoride [PMSF]). Eluted protein fractions were not sufficiently pure. Therefore, the most pure fractions, containing a total of $\sim 4 \mathrm{mg}$ protein, were further purified by ion exchange chromatography on Vivapure Q mini spin columns according to the instructions of the supplier. Fractions that were eluted by $\mathrm{NaCl}$ at concentrations between 0.15 and $0.25 \mathrm{mM}$ were free of most of the contaminants that were present after $\mathrm{Ni}$-agarose purification and were used in subsequent experiments.

pAp-phosphatase activity was assayed as previously described (Mechold et al. 2006), using separation of pAp from AMP by polyethyleneimine (PEI) thin-layer chromatography and visualization by ultraviolet light.

Activity assays on nanoRNA were performed using custommade RNA oligos labeled at their 5 '-end with the sulfoindocyanine succinimidyl ester cyanine 5 (Cy5) as previously described (Mechold et al. 2007). Assays on longer substrate were done using a custom-made RNA 24-mer (5'-CACACACACACACACACACA CACA- $\left.3^{\prime}\right)$ that was $5^{\prime}$-end labeled with $\left[\gamma^{-}{ }^{33} \mathrm{P}\right] \mathrm{ATP}$ as previously described (Fang et al. 2009). Labeling of the Decade-marker was performed as described previously (Mechold et al. 2007). The alkaline hydrolysis control was generated using the MirVana Probe and Marker Kit according to the instructions of the supplier. 


\section{SUPPLEMENTAL MATERIAL}

Supplemental material is available for this article.

\section{ACKNOWLEDGMENTS}

We thank Richard Herrmann for providing the cosmid to clone $m p n 140$, Jana Kordulakova for the gift of chromosomal DNA of M. tuberculosis H37Rv, and Indranil Biswas for supplying us with the plasmids expressing SMU.1297 and the corresponding vector controls. We thank Linda Pritchard, Vasily Ogryzko, and Scot Ouellette for carefully reading the manuscript. Part of this work was supported by MICROME, a Collaborative Project funded by the European Commission within its FP7 Program, under the thematic area "BIO-INFORMATICS-Microbial genomics and bio-informatics," contract no. 222886-2.

Received July 5, 2011; accepted October 17, 2011.

\section{REFERENCES}

Amblar M, Barbas A, Fialho AM, Arraiano CM. 2006. Characterization of the functional domains of Escherichia coli RNase II. J Mol Biol 360: 921-933.

Amblar M, Barbas A, Gomez-Puertas P, Arraiano CM. 2007. The role of the S1 domain in exoribonucleolytic activity: Substrate specificity and multimerization. RNA 13: 317-327.

Bhave DP, Muse WB III, Carroll KS. 2007. Drug targets in mycobacterial sulfur metabolism. Infect Disord Drug Targets 7: 140-158.

Cheng ZF, Deutscher MP. 2002. Purification and characterization of the Escherichia coli exoribonuclease RNase R: Comparison with RNase II. J Biol Chem 277: 21624-21629.

Danchin A. 2009. A phylogenetic view of bacterial ribonucleases. Prog Mol Biol Transl Sci 85:1-41.

Dandekar T, Huynen M, Regula JT, Ueberle B, Zimmermann CU, Andrade MA, Doerks T, Sánchez-Pulido L, Snel B, Suyama M, et al. 2000. Re-annotating the Mycoplasma pneumoniae genome sequence: adding value, function and reading frames. Nucleic Acids Res 28: $3278-3288$.

Daßler T, Maier T, Winterhalter C, Böck A. 2000. Identification of a major facilitator protein from Escherichia coli involved in efflux of metabolites of the cysteine pathway. Mol Microbiol 36: 1101-1112.

Fang M, Zeisberg WM, Condon C, Ogryzko V, Danchin A, Mechold U. 2009. Degradation of nanoRNA is performed by multiple redundant RNases in Bacillus subtilis. Nucleic Acids Res 37: 5114-5125.

Frazão C, McVey CE, Amblar M, Barbas A, Vonrhein C, Arraiano CM, Carrondo MA. 2006. Unravelling the dynamics of RNA degradation by ribonuclease II and its RNA-bound complex. Nature 443: 110-114.

Ghosh S, Deutscher MP. 1999. Oligoribonuclease is an essential component of the mRNA decay pathway. Proc Natl Acad Sci 96: 4372-4377.

Glass JI, Assad-Garcia N, Alperovich N, Yooseph S, Lewis MR, Maruf M, Hutchison CA 3rd, Smith HO, Venter JC. 2006. Essential genes of a minimal bacterium. Proc Natl Acad Sci 103: 425-430.

Goldman SR, Sharp JS, Vvedenskaya IO, Livny J, Dove SL, Nickels BE. 2011. NanoRNAs prime transcription initiation in vivo. Mol Cell 42: 817-825.

Guzman LM, Belin D, Carson MJ, Beckwith J. 1995. Tight regulation, modulation, and high-level expression by vectors containing the arabinose $\mathrm{P}_{\mathrm{BAD}}$ promoter. J Bacteriol 177: 4121-4130.

Hatzios SK, Iavarone AT, Bertozzi CR. 2008. Rv2131c from Mycobacterium tuberculosis is a CysQ $3^{\prime}$-phosphoadenosine- $5^{\prime}$-phosphatase. Biochemistry 47: 5823-5831.

Himmelreich R, Hilbert H, Plagens H, Pirkl E, Li BC, Herrmann R. 1996. Complete sequence analysis of the genome of the bacterium Mycoplasma pneumoniae. Nucleic Acids Res 24: 4420-4449.
Hutchison CA, Peterson SN, Gill SR, Cline RT, White O, Fraser CM, Smith HO, Venter JC. 1999. Global transposon mutagenesis and a minimal Mycoplasma genome. Science 286: 2165-2169.

Kühner S, van Noort V, Betts MJ, Leo-Macias A, Batisse C, Rode M, Yamada T, Maier T, Bader S, Beltran-Alvarez P, et al. 2009. Proteome organization in a genome-reduced bacterium. Science 326: 1235-1240.

Kumar M, Chatterji D. 2008. Cyclic di-GMP: a second messenger required for long-term survival, but not for biofilm formation, in Mycobacterium smegmatis. Microbiology 154: 2942-2955.

Lutz R, Bujard H. 1997. Independent and tight regulation of transcriptional units in Escherichia coli via the LacR/O, the TetR/O and AraC/ $I_{1}-I_{2}$ regulatory elements. Nucleic Acids Res 25: 1203-1210.

Mechold U, Ogryzko V, Ngo S, Danchin A. 2006. Oligoribonuclease is a common downstream target of lithium-induced pAp accumulation in Escherichia coli and human cells. Nucleic Acids Res 34: 2364-2373.

Mechold U, Fang G, Ngo S, Ogryzko V, Danchin A. 2007. YtqI from Bacillus subtilis has both oligoribonuclease and pAp-phosphatase activity. Nucleic Acids Res 35: 4552-4561.

Neidhardt FC, Bloch PL, Smith DF. 1974. Culture medium for enterobacteria. J Bacteriol 119: 736-747.

Neuwald AF, Krishnan BR, Brikun I, Kulakauskas S, Suziedelis K, Tomcsanyi T, Leyh TS, Berg DE. 1992. cysQ, a gene needed for cysteine synthesis in Escherichia coli K-12 only during aerobic growth. J Bacteriol 174: 415-425.

Nickels BE, Dove SL. 2011. NanoRNAs: A class of small RNAs that can prime transcription initiation in bacteria. J Mol Biol 412: 772-781.

Niyogi SK, Datta AK. 1975. A novel oligoribonuclease of Escherichia coli. I. Isolation and properties. J Biol Chem 250: 7307-7312.

Que YA, Haefliger JA, Francioli P, Moreillon P. 2000. Expression of Staphylococcus aureus clumping factor A in Lactococcus lactis subsp. cremoris using a new shuttle vector. Infect Immun 68: 3516-3522.

Rachman H, Strong M, Ulrichs T, Grode L, Schuchhardt J, Mollenkopf H, Kosmiadi GA, Eisenberg D, Kaufmann SH. 2006. Unique transcriptome signature of Mycobacterium tuberculosis in pulmonary tuberculosis. Infect Immun 74: 1233-1242.

Schelle MW, Bertozzi CR. 2006. Sulfate metabolism in mycobacteria. Chembiochem 7: 1516-1524.

Schmidl SR, Gronau K, Hames C, Busse J, Becher D, Hecker M, Stülke J. 2010. The stability of cytadherence proteins in Mycoplasma pneumoniae requires activity of the protein kinase PrkC. Infect Immun 78: 184-192.

Vincent HA, Deutscher MP. 2006. Substrate recognition and catalysis by the exoribonuclease RNase R. J Biol Chem 281: 29769-29775.

Waites KB, Talkington DF. 2004. Mycoplasma pneumoniae and its role as a human pathogen. Clin Microbiol Rev 17: 697-728.

Wakamatsu T, Kim K, Uemura Y, Nakagawa N, Kuramitsu S, Masui R. 2011. Role of RecJ-like protein with $5^{\prime}-3^{\prime}$ exonuclease activity in oligo(deoxy)nucleotide degradation. J Biol Chem 286: 2807-2816.

Williams SJ, Senaratne RH, Mougous JD, Riley LW, Bertozzi CR. 2002. 5'-adenosinephosphosulfate lies at a metabolic branch point in mycobacteria. J Biol Chem 277: 32606-32615.

Young Park A, Elvin CM, Hamdan SM, Wood RJ, Liyou NE, Hamwood TE, Jennings PA, Dixon NE. 2008. Hydrolysis of the $5^{\prime}$-p-nitrophenyl ester of TMP by oligoribonucleases (ORN) from Escherichia coli, Mycobacterium smegmatis, and human. Protein Expr Purif 57: 180-187.

Yu D, Deutscher MP. 1995. Oligoribonuclease is distinct from the other known exoribonucleases of Escherichia coli. J Bacteriol 177: 4137-4139.

Yus E, Maier T, Michalodimitrakis K, van Noort V, Yamada T, Chen WH, Wodke JA, Güell M, Martínez S, Bourgeois R, et al. 2009. Impact of genome reduction on bacterial metabolism and its regulation. Science 326: 1263-1268.

Zhang J, Biswas I. 2009. 3'-Phosphoadenosine-5'-phosphate phosphatase activity is required for superoxide stress tolerance in Streptococcus mutans. J Bacteriol 191: 4330-4340.

Zhang X, Zhu L, Deutscher MP. 1998. Oligoribonuclease is encoded by a highly conserved gene in the $3^{\prime}-5^{\prime}$ exonuclease superfamily. J Bacteriol 180: 2779-2781. 

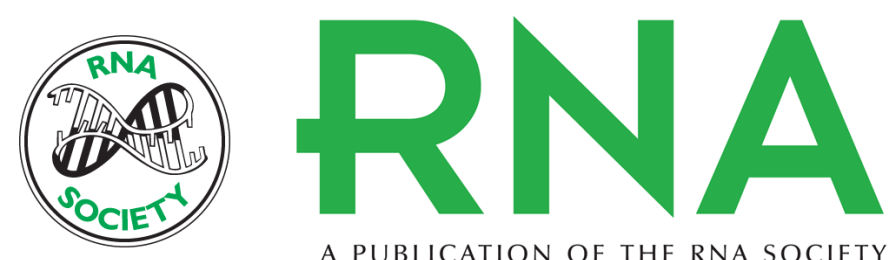

A PUBLICATION OF THE RNA SOCIETY

\section{Characterization of NrnA homologs from Mycobacterium tuberculosis and Mycoplasma pneumoniae}

Guillaume Postic, Antoine Danchin and Undine Mechold

RNA 2012 18: 155-165 originally published online November 23, 2011

Access the most recent version at doi:10.1261/rna.029132.111

\section{Supplemental http://rnajournal.cshlp.org/content/suppl/2011/11/08/rna.029132.111.DC1 \\ Material}

References This article cites 38 articles, 21 of which can be accessed free at:

http://rnajournal.cshlp.org/content/18/1/155.full.html\#ref-list-1

\section{License}

Email Alerting Receive free email alerts when new articles cite this article - sign up in the box at the Service top right corner of the article or click here.

\section{|||||||| Providing Precise Solutions for your research.}

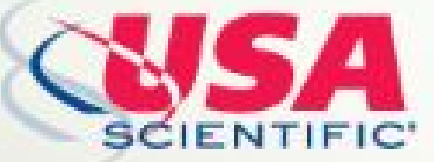

To subscribe to $R N A$ go to:

http://rnajournal.cshlp.org/subscriptions 